Pacific Journal of Mathematics

ON SOME NEW GENERALIZATIONS OF SHANNON'S
INEQUALITY 


\title{
ON SOME NEW GENERALIZATIONS OF SHANNON'S INEQUALITY
}

\author{
PAL Fischer
}

Let $A_{n}=\left\{P \in R^{n}: P=\left(p_{1}, p_{2}, \cdots, p_{n}\right)\right.$, where $\sum_{t=1}^{n} p_{t}=1$ and $p_{i}>0$ for $\left.i=1,2, \cdots, n\right\}$ and let $B_{n}=\left\{P \in A_{n}: p_{1} \geqq p_{2} \geqq\right.$ $\left.\cdots \geqq p_{n}\right\}$. We show that the inequality

$$
\sum_{i=1}^{n} p_{i} f\left(p_{i}\right) \geqq \sum_{i=1}^{n} p_{i} f\left(q_{i}\right)
$$

for all $P, Q \in B_{n}$ and some integer $n \geqq 3$, implies that $f(p)=$ $c \log p+d$, where $c$ is an arbitrary nonnegative number and $d$ is an arbitrary real number. We show, furthermore, that if we restrict the domain of the inequality (1) to those $P, Q \in B_{n}$ for which $P>Q$ (Hardy-Littlewood-Pólya order), then any function that is convex and increasing satisfies (1).

1. Let $P, Q \in A_{n}$. Then the inequality

$$
\sum_{i=1}^{n} p_{i} \log p_{i} \geqq \sum_{i=1}^{n} p_{i} \log q_{i}
$$

holds with equality iff $P=Q$ [9]. The inequality (2) has numerous applications in information theory [1]. Conversely, it was proved in [3], that the so-called Shannon-inequality

$$
\sum_{i=1}^{n} p_{i} f\left(p_{\imath}\right) \geqq \sum_{i=1}^{n} p_{\imath} f\left(q_{\imath}\right)
$$

for all $P, Q \in A_{n}$ and some integer $n \geqq 3$, implies that

$$
f(p)=c \log p+d \quad \text { for } \quad p \in(0,1)
$$

where $c$ is some nonnegative number and $d$ is some real number.

The inequality (3) has other interpretations, too. Let us mention the following. Let $E_{1}, E_{2}, \cdots, E_{n}$ be a mutually exclusive and complete system of the events of an experiment with the probability distribution $\left(p_{1}, p_{2}, \cdots, p_{n}\right)$ with positive probabilities. Let $q_{1}, q_{2}, \cdots, q_{n}$ be the estimates of these probabilities $\left(q_{1}>0\right.$ for $\left.i=1, \cdots, n\right)$. If the $i$ th event 
occurs then the experiment results in the payment of $f\left(q_{t}\right)$. The pay-off function $f$ must be chosen in such a way that the expected pay-off is maximized if the estimates coincide with the a priori distribution.

In some cases it is natural to modify this prescribed model. If the forecaster knows that $p_{1} \geqq p_{2} \geqq \cdots \geqq p_{n}$, then evidently the estimation will be made so that $q_{1} \geqq q_{2} \geqq \cdots \geqq q_{n}$. That way we restrict the domain of the inequality (1). A further restriction for the domain can be made by allowing $P, Q$ pairs such that $P, Q \in B_{n}$ and $P>Q$, i.e.

$$
\sum_{i=1}^{k} p_{\imath} \geqq \sum_{i=1}^{k} q_{i} \quad(k=1,2, \cdots, n),
$$

in addition to the conditions that define $B_{n}$.

The subject of this paper is to investigate the inequality (1) under these two types of restrictions. Similar types of inequalities are the topics of some recent papers, [4], [5], [6], [7].

2. In this section we consider the inequality (1) for all $P, Q \in B_{n}$ in the case when $n=2$. In that case (1) reduces to

$$
p f(p)+(1-p) f(I-p) \geqq p f(q)+(1-p) f(1-q)
$$

for all $1>p \geqq \frac{1}{2}, 1>q \geqq \frac{1}{2}, f:(0,1) \rightarrow R$. It is easy to see that

$$
f(1-q) \geqq f(1-p) \text { implies that } f(p) \geqq f(q) \text {. }
$$

By changing the roles of $p$ and $q$ in (5) and adding the thus obtained inequality to (5), we obtain

$$
(p-q)[f(p)-f(q)] \geqq(q-p)[f(1-q)-f(1-p)] .
$$

Assume that $1>p>q \geqq \frac{1}{2}$ and $f(p)<f(q)$, then by (6) we get a contradiction. Therefore $f$ is increasing on $\left[\frac{1}{2}, 1\right)$, and by using (6) again we see that $f$ is increasing on $(0,1)$. Since in the previous argument 1 can be replaced by any positive number, and 0 can be replaced by any positive number $b<a / 2$, we have shown the first part of the following theorem.

THEOREM 1. The general solution of the inequality

$$
p_{1} f\left(p_{1}\right)+p_{2} f\left(p_{2}\right) \geqq p_{1} f\left(q_{1}\right)+p_{2} f\left(q_{2}\right)
$$

for all $p_{1} \geqq p_{2} \geqq b, q_{1} \geqq q_{2} \geqq b, p_{1}+p_{2}=a, q_{1}+q_{2}=a, f:(b, a-b) \rightarrow R$, is 
increasing in the interval $(b, a-b)$, where $a$ and $b$ are fixed nonnegative numbers, $b<a / 2$. Furthermore, if $f$ is differentiable at a point $p \in$ $(b, a-b)$, then it is differentiable at $a-p$, too, and

$$
p f^{\prime}(p)=(a-p) f^{\prime}(a-p) .
$$

Proof. According to our previous remark, we have to show only the second part of this theorem.

Without loss of generality we can assume that $p>a / 2$. Setting first $p_{1}=p+h, q_{1}=p$ and setting secondly $p_{1}=p$ and $q_{1}=p+h$ in the inequality (8), where $|h|$ is sufficiently small, we obtain

$$
\frac{p+h}{a-p-h}[f(p+h)-f(p)] \geqq f(a-p)-f(a-p-h)
$$

$$
\geqq \frac{p}{a-p}[f(p+h)-f(p)]
$$

Dividing (10) by $h \neq 0$, and tending with $h$ to 0 , we obtain the proof of this theorem.

3. In this section we consider the inequality (1) for all $P, Q \in B_{n}$ in the case where $n \geqq 3$. We prove the following theorem.

THEOREM 2. Let $f:(0,1) \rightarrow R$. Then $f$ satisfies the inequality

$$
\sum_{i=1}^{n} p_{i} f\left(p_{i}\right) \geqq \sum_{i=1}^{n} p_{i} f\left(q_{i}\right)
$$

for all $P, Q \in B_{n}$, where $n$ is a fixed positive integer, $n \geqq 3$ only if $f$ has the form $f(p)=c \log p+d$, where $c$ is an arbitrary nonnegative number and $d$ is an arbitrary real number.

Proof. First we show that $f$ is increasing in $(0,1)$. Let $p_{3}=\cdots=$ $p_{n}=q_{3}=\cdots=q_{n}<1 / n$. Then (11) reduces to

$$
p_{1} f\left(p_{1}\right)+p_{2} f\left(p_{2}\right) \geqq p_{1} f\left(q_{1}\right)+p_{2} f\left(q_{2}\right)
$$

for $\quad$ all $\quad p_{1} \geqq p_{2} \geqq p_{3}, \quad q_{1} \geqq q_{2} \geqq p_{3} \quad$ such that $p_{1}+p_{2}=q_{1}+q_{2}=$ $1-(n-2) p_{3}$. By Theorem 1 we can conclude that $f$ is increasing in the interval $\left(p_{3}, 1-(n-1) p_{3}\right)$. Since we can choose $p_{3}$ to be arbitrarily small positive number we see that $f$ is increasing in the interval $(0,1)$.

Secondly we show that $f$ is differentiable in $(0,1)$. Assume that 
there exists a point $p_{0}$ where $f$ is not differentiable, then by choosing $a>p_{0}, p_{3}=q_{3}=\cdots=p_{n}=q_{n}<\min \left(p_{0}, a-p_{0}\right)$, we see by Theorem 1 that $f$ is not differentiable at $a-p_{0}$. By changing $a$ and $p_{3}=\cdots=q_{n}$ adequately the set of points $a-p_{0}$ forms a set of positive measure, but this is impossible because, according to a theorem of Lebesgue, an increasing function is differentiable almost everywhere.

Finally, by Theorem 1 we can conclude, that $p f^{\prime}(p)=\frac{1}{2} f^{\prime}\left(\frac{1}{2}\right)$ for all $p \in(0,1)$, that is

$$
p f^{\prime}(p) \equiv c \text { for all } p \in(0,1)
$$

where $c$ is nonnegative, since $f$ is increasing. From (13) this theorem follows immediately.

4. In this section we make further restrictions to the domain of the inequality (1). We shall need the following lemma.

LEMMA 1. Let $a_{1}, a_{2}, \cdots, a_{n}$ be a sequence of reals such that

$$
s_{k}=\sum_{i=1}^{k} a_{t} \geqq 0 \quad \text { for } \quad 1 \leqq k \leqq n .
$$

Let $\lambda_{1} \geqq \lambda_{2} \geqq \cdots \geqq \lambda_{n} \geqq 0$ be a sequence of reals. Then $\sum_{i=1}^{n} \lambda_{l} a_{l} \geqq 0$.

Proof. This lemma is implicitly contained in Lemmas 3 and 5 in [7].

Now we shall prove a theorem, which is analogous to a result of $\mathrm{L}$. Fuchs [8].

THEOREM 3. Let $x_{1} \geqq \cdots \geqq x_{n}, y_{1} \geqq \cdots \geqq y_{n}$ be arbitrary real num bers, and let $p_{1}, \cdots, p_{n}$ be arbitrary nonnegative numbers. Then the inequality

$$
\sum_{i=1}^{n} p_{i} f\left(x_{i}\right) \geqq \sum_{i=1}^{n} p_{i} f\left(y_{i}\right)
$$

holds for every continuous convex and increasing function $f:\left[\left(\min \left(x_{n}, y_{n}\right), \max \left(x_{1}, y_{1}\right)\right] \rightarrow R\right.$ if

$$
\sum_{i=1}^{k} p_{i} x_{i} \geqq \sum_{i=1}^{k} p_{i} y_{i} \quad \text { for } \quad k=1, \cdots, n \text {. }
$$

Proof. Since $f$ is a continuous convex and increasing function on the interval $\left[\left(\min \left(x_{n}, y_{n}\right), \max \left(x_{1}, y_{1}\right)\right]\right.$, there is on the interval 
$\left[\min \left(x_{n}, y_{n}\right), \max \left(x_{1}, y_{1}\right)\right)$ an increasing and nonnegative function $h$ such that

$$
f(p)=c+\int_{\alpha}^{p} h(q) d q
$$

where $\alpha \in\left(\min \left(x_{n}, y_{n}\right), \max \left(x_{1}, y_{1}\right)\right)$. It may be necessary to interpret (17) as an improper integral when $p$ is an endpoint.

In order to show the inequality (15), we have to establish that

$$
\sum_{i=1}^{n} p_{\imath}\left(f\left(x_{i}\right)-f\left(y_{i}\right)\right)=\sum_{i=1}^{n} p_{i} \int_{y_{i}}^{x_{i}} h(q) d q \geqq 0,
$$

or equivalently, we have to show that

$$
\sum_{x_{i} \geq y_{t}} p_{i} \int_{y_{t}}^{x_{i}} h(q) d q \geqq \sum_{x_{i}<y_{t}} p_{i} \int_{x_{t}}^{y_{i}} h(q) d q
$$

Using the fact that $h$ is increasing, we see that

$$
\sum_{x_{i}<y_{t}} p_{i} \int_{x_{i}}^{y_{t}} h(q) d q \leqq \sum_{x_{i}<y_{t}} p_{i}\left(y_{t}-x_{t}\right) h\left(y_{t}\right)
$$

and

$$
\sum_{x_{t} \geq y_{t}} p_{t} \int_{y_{i}}^{x_{i}} h(q) d q \geqq \sum_{x_{t} \geqq y_{i}} p_{t}\left(x_{t}-y_{i}\right) h\left(y_{i}\right)
$$

In order to prove (18) it is sufficient to show that

$$
\sum_{x_{i} \geqq y_{i}} p_{i}\left(x_{i}-y_{i}\right) h\left(y_{i}\right) \geqq \sum_{x_{1} \geqq y_{i}} p_{i}\left(y_{i}-x_{i}\right) h\left(y_{i}\right),
$$

that is to show that

$$
\sum_{i=1}^{n}\left(x_{i}-y_{i}\right) p_{i} h\left(y_{i}\right) \geqq 0 .
$$

Lemma 1 yields (23) by letting $p_{i}\left(x_{t}-y_{i}\right)=a_{i}$ and $h\left(y_{i}\right)=\lambda_{t}$ for $1 \leqq i \leqq n$.

The following lemma can be found implicitly in Mitrinović [10, pp. 337-338]. 
LEMMA 2. Let $b_{1}, b_{2}, \cdots, b_{n}$ be real numbers, let $a_{1} \geqq \cdots \geqq a_{n} \geqq 0$, and let

$$
\sum_{i=1}^{k} a_{i} \leqq \sum_{i=1}^{k} b_{l} \quad \text { for } \quad k=1, \cdots, n
$$

Then $\sum_{t=1}^{n} a_{t}^{2} \leqq \sum_{t=1}^{n} a_{t} b_{i} \leqq \sum_{t=1}^{n} b_{\imath}^{2}$.

Now, we can prove the main result of this section.

THEOREM 4. Any increasing and convex function $f:(0,1) \rightarrow R$ satisfies the inequality

$$
\sum_{i=1}^{n} p_{i} f\left(p_{\imath}\right) \geqq \sum_{i=1}^{n} p_{i} f\left(q_{i}\right)
$$

for all $P, Q \in B_{n}, P>Q$.

Proof. Let $P, Q \in B_{n}, P>Q$, then by Lemma 2

$$
\sum_{i=1}^{n} p_{i} q_{i} \leqq \sum_{i=1}^{n} p_{i}^{2}
$$

Therefore, according to Theorem 3 , by setting $x_{1}=p_{1}, y_{t}=q_{1}$ into (16) $(i=1, \cdots, n)$ we see that any increasing and convex function $f$ satisfies $(25)$, since $f$ is continuous on $\left[\min \left(p_{n}, q_{n}\right), p_{1}\right]$.

5. In the previous section we have shown that any convex and increasing function satisfies (1) for all $P, Q \in B_{n}$ such that $P>Q$. In this section we establish the same result by an alternative proof without the use of any additional lemmas.

Alternative proof. Since $f$ is increasing and convex, $f$ has an integral representation of the form

$$
f(p)=\alpha_{0}+\int_{\alpha}^{p} h(t) d t, \quad \alpha \in(0,1)
$$

where $h$ is nonnegative and increasing function on $(0,1)$. In order to prove (25), we have to show that

$$
\Sigma p_{i}\left[f\left(p_{i}\right)-f\left(q_{i}\right)\right]=\Sigma p_{i} \int_{q_{r}}^{p_{1}} h(t) d t \geqq 0 ;
$$

equivalently, we have to show that 


$$
\sum_{p_{i} \geqq q_{i}} p_{i} \int_{q_{i}}^{p_{i}} h(t) d t \geqq \sum_{p_{i}<q_{i}} p_{i} \int_{p_{i}}^{q_{i}} h(t) d t
$$

We see that

$$
\sum_{p_{i} \geq q_{t}}\left(p_{i}-q_{t}\right)=\sum_{q_{t}>p_{t}}\left(q_{t}-p_{t}\right)
$$

and

$$
\sum_{\substack{p_{i} \geqq q_{i} \\ 1 \leqq l \leqq k}}\left(p_{i}-q_{1}\right) \geqq \sum_{\substack{q_{1}>p_{1} \\ 1 \leqq l \leqq k}}\left(q_{i}-p_{i}\right)
$$

for $1 \leqq k \leqq n$. Let $i_{1}$ be the smallest index $i$ for which $q_{i}>p_{1}$, let $i_{2}$ be the smallest index $i$ such that $i_{2}>i_{1}$ and $p_{l}>q_{l}$, let $i_{3}$ be the smallest index $i$ such that $i_{3}>i_{2}$ and $q_{1}>p_{1}$, and so on. We shall show that

$$
\sum_{i=1}^{i_{1}-1} p_{\imath} \int_{q_{t}}^{p_{t}} h(t) d t \geqq \sum_{i=l_{1}}^{i_{2}-1} p_{\imath} \int_{p_{t}}^{q_{t}} h(t) d t
$$

Furthermore if $\sum_{t=1}^{i_{1}-1}\left(p_{t}-q_{t}\right)>\sum_{l=l}^{l_{1}-1}\left(q_{t}-p_{t}\right)$, we shall show that

$$
\sum_{i=1}^{i t-1} p_{i} \int_{q_{i}^{*}}^{p_{t}} h(t) d t \geqq \sum_{i=i_{1}}^{i_{2}-1} p_{t} \int_{p_{t}}^{q_{t}} h(t) d t
$$

where $q_{i}^{*}=q_{i}$ for all $i \leqq i_{1}^{*}-1$, except possibly for $i=i_{1}^{*}-1$, and $i_{1}^{*}-1$ and $q_{i,-1}^{*}$ are determined by the relation

$$
\sum_{i=1}^{i+1}\left(p_{i}-q_{i}^{*}\right)=\sum_{i=l_{i}}^{i_{2}-1}\left(q_{i}-p_{i}\right)
$$

(This last relation determines $i_{1}^{*}$ uniquely, unless $p_{i}=q_{1}$ for some $i$, but in this latter case we can choose any of these indices.)

To prove (28), we remark that any interval of the type $\left(q^{*}, p_{t}\right)$ is to the right of the interval $\left(p_{i}, q_{i}\right)$ for $i_{1} \leqq i \leqq i_{2}-1$ and that $\left\{p_{i}\right\}$ is a nonnegative and decreasing sequence. These things, together with the fact that $h$ is a nonnegative and increasing function, prove (28). The next step of the proof consists in showing that

$$
p_{i \uparrow}-1 \int_{q_{i 1-1}}^{q_{i+1}^{*}} h(t) d t+\sum_{i=i \uparrow}^{i_{1}-1} p_{i} \int_{q_{i}}^{p_{i}} h(t) d t+\sum_{i=l_{2}}^{l_{i}-1} p_{i} \int_{q_{i}}^{p_{i}} h(t) d t
$$

$$
\geqq \sum_{i=l_{3}}^{l_{4}-1} p_{i} \int_{p_{i}}^{q_{1}} h(t) d t
$$


and in proving the analogue of inequality (28) if

$$
\sum_{i=1}^{t_{t}-1}\left(p_{i}-q_{i}\right)+\sum_{i=t_{2}}^{t_{3}-1}\left(p_{i}-q_{i}\right)>\sum_{i=i_{1}}^{t_{2}-1}\left(q_{t}-p_{i}\right)+\sum_{i=i_{3}}^{t_{4}-1}\left(q_{t}-p_{i}\right) .
$$

By repeating the argument we obtain the proof of this theorem.

6. With the aid of simple examples one can see that (1) may fail for some $P, Q \in B_{n}$ with $P>Q$ if we assume that $f$ is merely increasing, or that $f$ is merely convex, or merely concave.

We shall next present, some related inequalities which may be of independent interest.

We need the following lemma.

LEMMA 3. Let $u_{1}, u_{2}, \cdots, u_{n}$ be a sequence of real numbers such that

$$
S_{k}=\sum_{i=1}^{k} u_{i} \geqq 0 \quad \text { for } \quad 1 \leqq k \leqq n-1
$$

and

$$
S_{n}=\sum_{i=1}^{n} u_{t}=0
$$

Let $0 \leqq \lambda_{1} \leqq \lambda_{2} \leqq \cdots \leqq \lambda_{n}$, then

$$
\sum_{i=1}^{n} \lambda_{l} u_{i} \leqq 0
$$

Proof. The relation (31) implies that $\lambda_{1} u_{1}+\lambda_{1} \sum_{t=2}^{n} u_{t}=0$. Clearly $\sum_{i=k}^{n} u_{i} \leqq 0$ for $1 \leqq k \leqq n$. Therefore

$$
\begin{aligned}
& \lambda_{1} \sum_{i=2}^{n} u_{i} \geqq \lambda_{2} \sum_{i=2}^{n} u_{i}, \quad \text { i.e. } \\
& 0 \geqq \lambda_{1} u_{1}+\lambda_{2} u_{2}+\lambda_{2} \sum_{i=3}^{n} u_{i} .
\end{aligned}
$$

By repeating the argument we obtain the proof of this lemma.

Our next result will show, among other things, that the function $f(p)=1 / p^{\alpha}(\alpha \geqq 1)$ satisfies the inequality (1) for all $P, Q \in B_{n}, P>Q$.

Theorem 5. Let $P, Q \in B_{n}, P>Q$. Then 


$$
\sum_{i=1}^{n} \frac{p_{i}}{q_{i}^{\alpha}} \leqq \sum_{i=1}^{n} \frac{1}{q_{i}^{\alpha-1}} \leqq \sum_{i=1}^{n} \frac{1}{p_{i}^{\alpha-1}} \quad \text { where } \quad \alpha \geqq 1
$$

Proof. The right-hand side of (33) is, of course, well-known; we mention it only because it shows that $1 / p^{\alpha}$ for $\alpha \geqq 1$ satisfies (1) for all $P, Q \in B_{n}, \quad P>Q$. It is a special case of a theorem of Hardy-Littlewood-Pólya, which says that if $P>Q, p_{1} \geqq p_{2} \geqq \cdots \geqq p_{n}$, $q_{1} \geqq \cdots \geqq q_{n}$, and $f:\left[p_{n}, p_{1}\right] \rightarrow R$ is a continuous and convex function, then

$$
\sum_{i=1}^{n} f\left(p_{i}\right) \geqq \sum_{i=1}^{n} f\left(q_{i}\right)
$$

Let $u_{t}=p_{t}-q_{t}$ for $i=1,2, \cdots, n$. It is easy to see that $\sum_{i=1}^{k} u_{t} \geqq 0$ for $1 \leqq k \leqq n-1$ and $\sum_{i=1}^{n} u_{\imath}=0$. Thus

$$
\sum_{i=1}^{n} \frac{p_{i}}{q_{i}^{\alpha}}=\sum_{i=1}^{n} \frac{u_{i}}{q_{i}^{\alpha}}+\sum_{i=1}^{n} \frac{1}{q_{i}^{\alpha-1}} \leqq \sum_{i=1}^{n} \frac{1}{q_{i}^{\alpha-1}}
$$

since by Lemma $3 \sum_{i=1}^{n} u_{\imath} / q_{i}^{\alpha} \leqq 0$.

Finally we note two special cases of the previous theorem. If $P, Q \in B_{\mathrm{n}}$ and $P>Q$, then

$$
\sum_{i=1}^{n} \frac{p_{i}}{q_{t}} \leqq n
$$

and

$$
\sum_{i=1}^{n} \frac{p_{i}}{q_{i}^{2}} \leqq \sum_{i=1}^{n} \frac{1}{q_{i}}
$$

\section{REFERENCES}

1. R. Ash, Information Theory, Interscience Publishers, 1965.

2. P. Fischer, On the inequality $\Sigma p_{1} f\left(p_{1}\right) \geqq \Sigma p_{t} f\left(q_{t}\right)$, Metrika, 18 (1972), 199-208.

3. - On the inequality $\Sigma g\left(p_{t}\right) f\left(p_{\imath}\right) \geqq \Sigma g\left(p_{t}\right) f\left(q_{t}\right)$, Aequationes Math., 10 (1974), 23-33.

4. —- On the inequality $\Sigma p_{\imath} f\left(p_{1}\right) / f\left(q_{1}\right) \leqq 1$, Canad. Math. Bull. 17 (1974), 193-199.

5. Sur l'inégalité $\Sigma\left[p_{1} f\left(p_{t}\right)+q_{t} f\left(q_{t}\right)\right] \geqq\left[p_{t} f\left(q_{t}\right)+q_{1} f\left(p_{i}\right)\right]$, Period. Hungar., $5(1974), 87-92$.

6. - On the inequality $\Sigma p_{1} f\left(p_{1}\right) / f\left(q_{1}\right) \geqq 1$, Pacific J. Math., 60 (1975), 65-74.

7. P. Fisher and J. A. R. Holbrook, Matrices doubly stochastic by blocks, Canad. J. Math., 29 No. 3 (1977), 559-571.

8. L. Fuchs, A new proof of an inequality of Hardy-Littlewood-Pólya, Mat. Tidsskr. B (1947), $53-54$. 
9. P. G. Kirmser, Problem E 1274, Amer. Math. Monthly, 64 (1957).

10. D. S. Mitrinović, Analytic Inequalities, Springer-Verlag, 1970.

Received April 20, 1977.

UNIVERSITY OF GUELPH

Guelph, Ontario, Canada 


\section{PACIFIC JOURNAL OF MATHEMATICS \\ EDITORS}

RICHARD ARENS (Managing Editor)

University of California

Los Angeles, CA 90024

\section{R. A. Beaumont \\ University of Washington \\ Seattle, WA 98105}

C. C. MOORE

University of California

Berkeley, CA 94720

\section{J. DUGUNDJI}

Department of Mathematics

University of Southern California

Los Angeles, CA 90007

R. FINN AND J. MILGRAM

Stanford University

Stanford, CA 94305

\section{ASSOCIATE EDITORS}

\section{E. F. BECKENBACH}

B. H. NeUmanN

F. WOLF

K. YoSHIDA

\section{SUPPORTING INSTITUTIONS}

\author{
UNIVERSITY OF BRITISH COLUMBIA \\ CALIFORNIA INSTITUTE OF TECHNOLOGY \\ UNIVERSITY OF CALIFORNIA \\ MONTANA STATE UNIVERSITY \\ UNIVERSITY OF NEVADA \\ NEW MEXICO STATE UNIVERSITY \\ OREGON STATE UNIVERSITY \\ UNIVERSITY OF OREGON \\ OSAKA UNIVERSITY
}

\author{
UNIVERSITY OF SOUTHERN CALIFORNIA \\ STANFORD UNIVERSITY \\ UNIVERSITY OF HAWAII \\ UNIVERSITY OF TOKYO \\ UNIVERSITY OF UTAH \\ WASHINGTON STATE UNIVERSITY \\ UNIVERSITY OF WASHINGTON \\ AMERICAN MATHEMATICAL SOCIETY
}

The Supporting Institutions listed above contribute to the cost of publication of this Journal, but they are not owners or publishers and have no responsibility for its contents or policies.

Mathematical papers intended for publication in the Pacific Journal of Mathematics should be in typed form or offset-reproduced (not dittoed), double spaced with large margins. Underline Greek letters in red, German in green, and script in blue. The first paragraph or two must be capable of being used separately as a synopsis of the entire paper. Items of the bibliography should not be cited there unless absolutely necessary, in which case they must be identified by author and Journal, rather than by item number. Manuscripts, in duplicate, may be sent to any one of the four editors. Please classify according to the scheme of Math. Reviews, Index to Vol. 39. All other communications should be addressed to the managing editor, or Elaine Barth, University of California, Los Angeles, California, 90024.

100 reprints are provided free for each article, only if page charges have been substantially paid. Additional copies may be obtained at cost in multiples of 50 .

The Pacific Journal of Mathematics is issued monthly as of January 1966. Regular subscription rate: $\$ 72.00$ a year (6 Vols., 12 issues). Special rate: $\$ 36.00$ a year to individual members of supporting institutions.

Subscriptions, orders for back numbers, and changes of address should be sent to Pacific Journal of Mathematics, 103 Highland Boulevard, Berkeley, California, 94708.

PUBLISHED BY PACIFIC JOURNAL OF MATHEMATICS, A NON-PROFIT CORPORATION

Printed at Jerusalem Academic Press, POB 2390, Jerusalem, Israel.

Copyright (C) 1977 Pacific Journal of Mathematics All Rights Reserved 


\section{Pacific Journal of Mathematics \\ Vol. 70, No. $2 \quad$ October, 1977}

B. Arazi, A generalization of the Chinese remainder theorem ........... 289

Thomas E. Armstrong, Polyhedrality of infinite dimensional cubes .... . . . 297

Yoav Benyamini, Mary Ellen Rudin and Michael L. Wage, Continuous

images of weakly compact subsets of Banach spaces ............ 309

John Thomas Burns, Curvature functions on Lorentz 2-manifolds ......... 325

Dennis F. De Riggi and Nelson Groh Markley, Shear distality and equicontinuity .................................. 337

Claes Fernström, Rational approximation and the growth of analytic

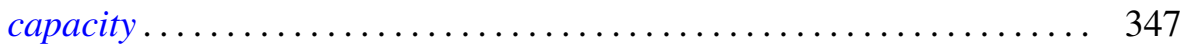

Pál Fischer, On some new generalizations of Shannon's inequality....... 351

Che-Kao Fong, Quasi-affine transforms of subnormal operators ......... 361

Stanley P. Gudder and W. Scruggs, Unbounded representations of

*-algebras........................................ 369

Chen F. King, A note on Drazin inverses .................... 383

Ronald Fred Levy, Countable spaces without points of first countability . . . 391

Eva Lowen-Colebunders, Completeness properties for convergence

spaces ......................................... 401

Calvin Cooper Moore, Square integrable primary representations ....... 413

Stanisław G. Mrówka and Jung-Hsien Tsai, On preservation of

E-compactness ................................ 429

Yoshiomi Nakagami, Essential spectrum $\Gamma(\beta)$ of a dual action on a von

Neumann algebra ................................ 437

L. Alayne Parson, Normal congruence subgroups of the Hecke groups

$G\left(2^{(1 / 2)}\right)$ and $G\left(3^{(1 / 2)}\right)$...

Louis Jackson Ratliff, Jr., On the prime divisors of zero in form rings . . . . 489

Caroline Series, Ergodic actions of product groups .................. 519

Robert O. Stanton, Infinite decomposition bases..................... 549

David A. Stegenga, Sums of invariant subspaces .................. 567 